\title{
Hepatic Lipofuscinosis in Healthy Norwegian Sheep
}

\author{
By Knut Nordstoga
}

Department of Pathology, Norwegian College of Veterinary Medicine, Oslo, Norway.

\begin{abstract}
Nordstoga, K.: Hepatic lipofuscinosis in healthy Norwegian sheep. Acta vet. scand. 1990, 31, 73-78. - Sheep livers with environmental pigmentation were examined histochemically and by electron microscopy. The pigment granules in hepatocytes and Kupffer cells had abundant lipid droplets; they were interpreted as being a variant of lipofuscins. It is concluded that the presently used descriptive term for the condition, "perilobular liver melanosis" should be replaced by the expression "liver lipofuscinosis".

pigmentation; sheep liver; electron microscopy.
\end{abstract}

\section{Introduction}

The first description of heavy liver pigmentation in otherwise healthy sheep is from Australia (Gilruth 1910); this pigment was identified as melanin. Unaware of Gilruth's studies, Buer (1940) reported a similar condition in Norwegian sheep; also he considered the pigment to be melanin. In both investigations, the pigment was found predominantly to be localized in the peripheral zone of the lobules, giving the livers a mottled appearance, each individual lobule thus having a brownish centre, and a darker brown periphery. Ovine hepatic pigmentation, with or without pigment deposits in other sites or clinical signs, has subsequently been described by a number of authors (Arias et al. 1964, de Saram et al. 1969, Krishna et al. 1972, Palmer et al. 1986, Schleger 1970a, b, Winter 1961). As there still seems to be some doubt regarding the true nature of the pigment, this work was undertaken to study the light and electron microscopic appearance of the hepatic pigment granules found in otherwise normal Norwegian sheep.

\section{Material and methods}

Brown livers from 4 sheep were obtained from 2 different slaughterhouses in the southwestern area of Norway, both situated in districts in which hepatic discolouration is a common finding. All animals were routinely slaughtered, in the usual manner, after electrical stunning and bleeding. Only the livers were available for examination.

\section{Light Microscopy}

The DOPA - reaction was performed on formalin-fixed frozen sections (Bancroft \& Stevens 1975).

Formalin-fixed hepatic tissues were embedded in paraffin according to routine procedures. The following staining methods or other techniques were used: Haematoxilin and eosin (HE), silver impregnation (Fontana and hexamine silver), Sudan black, Schmorl reaction, Long Ziehl-Neelsen, Periodic acid-Schiff (PAS), Nile blue sulphate, methylene blue, and a bleaching test $\left(\mathrm{H}_{2} \mathrm{O}_{2}\right)$. Unstained sections were examined in polarizeci and ultraviolet light.

\section{Electron Microscopy}

Specimens for electron microscopy were fixed in diluted Karnovsky fixative, the material then being embedded in Araldite after acetone dehydration and infiltration in Aral- 
Table 1. Histochemistry of the hepatic pigment.

\begin{tabular}{ll}
\hline Techniques & Results \\
\hline DOPA-reaction & negative \\
Silver impregnation $\left\{\begin{array}{l}\text { Fontana } \\
\text { Hexamine }\end{array}\right.$ & no evident alteration \\
Sudan black & negative \\
Schmorl reaction & dark blue granules \\
Long Ziehl-Neelsen & negative \\
PAS & negative \\
Nile blue sulphate & greenish blue granules \\
Methylene blue $\left(\mathrm{pH}_{9.4-2,6)}\right.$ & no evident binding \\
Bleaching test $\left(10 \% \mathrm{H}_{2} \mathrm{O}_{2}\right)$ & total bleaching after 48 hrs \\
\hline
\end{tabular}

dite. Semithin sections were stained with toluidine blue. Ultrathin sections stained with uranyl acetate and lead citrate were examined in a Jeol 100 S electron microscope.

\section{Results}

\section{Macroscopic Appearance}

The livers varied in colour from dull grey to dark brown, exhibiting a more or less obvious acinar pattern at the external surfaces (Fig. 1).

\section{Light Microscopy}

Histological examination revealed the presence of yellow-brown pigment granules in hepatocytes, often predominantly in the peripheral areas of the lobules; Kupffer cells were frequently distended, being laden with similar cytoplasmic granules (Figs. 2-3). The finely granular pigment retained its own colour in HE-sections. The granules were not double refractive when examined in polarized light, and did not exhibit autofluorescence in ultra violet light. Melanocytes were not seen in DOPA-sections.

Other results are summarized in Table 1.

\section{Electron Microscopy}

When viewed by electron microscopy, the granules appeared as irregular bodies, not always distinctly delimited from the adjacent cytoplasm by distinct membranes; the content of these granules was of somewhat varying electron density. Lipid droplets were frequently associated with the more electron dense material. Damaged mitochondria, in various stages of disintegration, were frequently observed (Figs. 4-7).

\section{Discussion}

Histochemical results in this study were largely in accord with reactions considered to be more or less specific for lipofuscins, the few deviations observed (such as lack of autofluorescence) probably being due to the heterogenity of this group of pigments. At the electron microscopic level, the pigment granules seemed to fulfill the criteria of lipofuscins (Ghadially 1982). The identification of the pigment is thus mainly based on electron microscopic findings, especially two observations, i.e. a), the abundance of lipid droplets in the pigment deposits, and b), the recognition that the pigment frequently was formed from degraded mitochondria (Fig. 5). Histochemical identification of mammalian pigments has been the subject of much controversy, and the differentiation between pigments belonging to the lipofuscin group and the melanins has been considered to be 
special problematical. An exact determination is also impeded by the circumstance that more types of pigments are sometimes present in the same location; this may also be the case in ovine hepatic pigmentations. The possibility of an association between lipofuscins and a type of melanin has long been considered (Krishna et al. 1972, Rowland \& Whiley 1983, Schleger 1970a). This could explain the uncertainty regarding the exact nature of the hepatic pigmentation found in otherwise healthy sheep. Elucidation of such an interrelationship requires, however, further studies. Another form of pigmentation, including heavy deposits also at extrahepatic sites and accompanied by clinical signs, such as retention of phylloerythrin and photosensitivity, occurs in mutant Corriedale sheep (Arias et al. 1964). There seems thus to be reasons to believe that the ovine species is prone to disturbances in pigment metabolism.

Histochemical analyses of lipofuscin granules show that the pigment is not composed of a homogenous substance or a single chemical compound (Ghadially 1982). Acid hydrolases have been demonstrated, and lipofuscin granules are considered to be lysosomal bodies (Skepper \& Navaratnam 1987, Travis \& Travis 1972).

Lipofuscins may accumulate in various organs in association with certain dietary conditions and ageing. In the veterinary pathology, accumulation of pigments belonging to the ceroid/lipofuscin group is well known in connection with diets containing high amounts of unsaturated fat, especially rancid fat. Residual bodies of the lipofuscin type may have a somewhat varying origin. It has, for example, been shown that lipofuscin granules within lysosomes in the myocardium, may, among other pathways, be formed from mitochondria (Skepper \& Navaratnam 1987, Travis \& Travis 1972). The observa- tions in this study that pigment granules may originate from degenerated mitochondria are thus in accord with studies in other animal species. In contrast, melanin synthesis occurs only in DOPA - positive melanocytes, containing melanosomes, which are organelles specialized for the production of melanin (Ghadially 1982).

This study did not produce indications of the etiological factors involved. The circumstances under which the condition occurs indicate that certain local soil types, or possibly specific types of vegetation in unimproved pastures are implicated, since many animals showing the condition have been grazing mountain pastures during the summer. No special breed seems to be predisposed. Little is known about the incidence of the pigmentation in recent years, but Buer (1940) reported that $1.9 \%$ of the animals in his material was affected.

The result of this study indicates that the descriptive term "perilobular liver melanosis" presently used to designate this frequently occurring hepatic pigmentation, should be replaced by the diagnostic name "liver lipofuscinosis". Although the lipid character of the pigment is beyond dispute, it must be borne in mind that the chemical composition is unknown, and that the material was limited. While "true" melanin is synthesized in melanocytes, by the enzymic oxidation of tyrosine, melanin-like substances may, in the absence of melanocytes, be produced by the oxidation of certain cyclic compounds, such as phenol, pyrogallol, indole and skatole (Ghadially 1982). There is thus perhaps a need for a more extensive investigation, including samples from other districts, before we can definitely conclude that melanin-like structures are never present in the pigment granules found in the livers of Norwegian sheep showing this condition. 

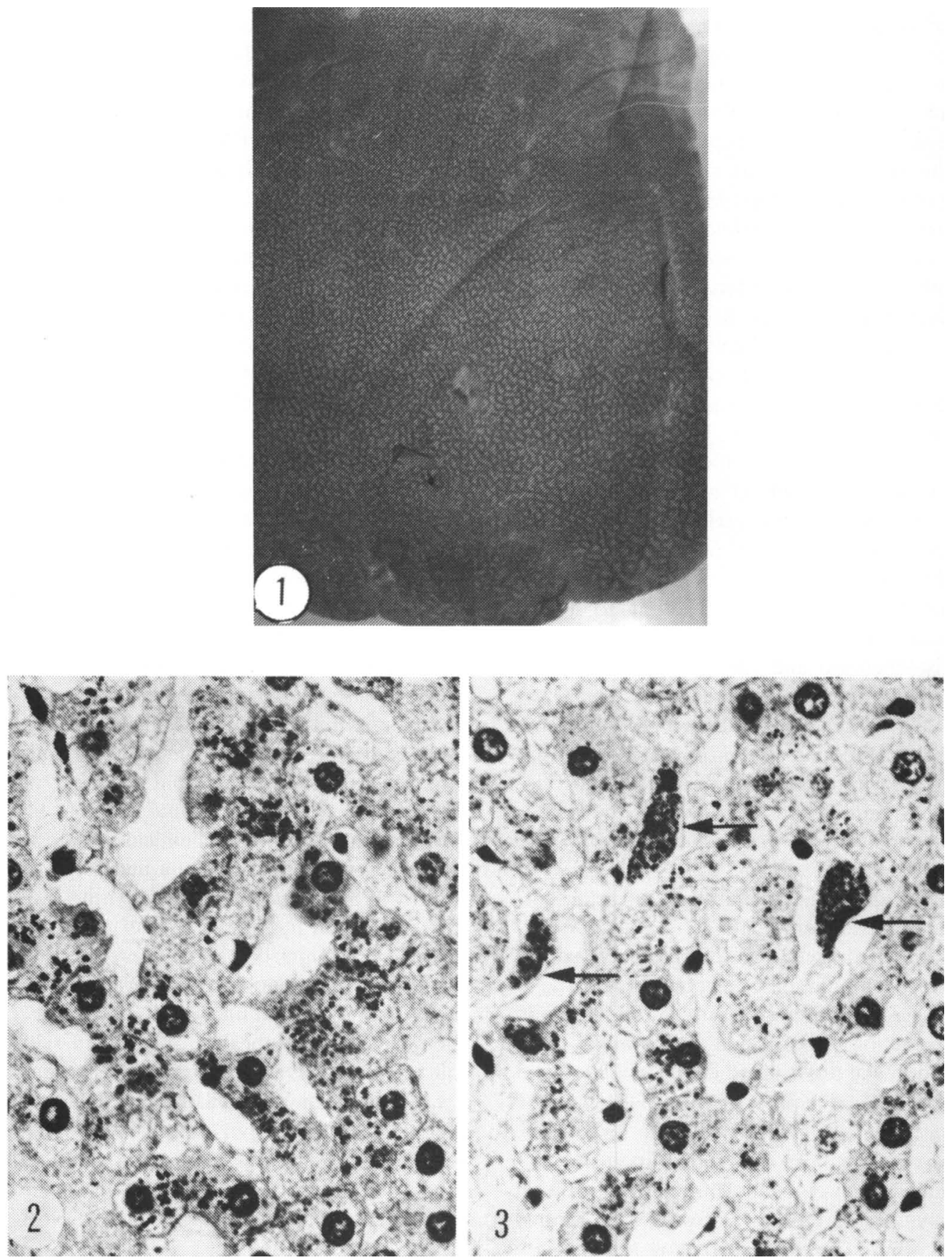

Figu re 1. Macroscopic liver changes; dark liver with acinar pattern.

Figu re 2. Pigment granules within the cytoplasm of hepatocytes. HE, $\times 670$.

Figure 3. Liver. Pigment granules in Kupffer cells (arrows). HE, $\times 670$. 


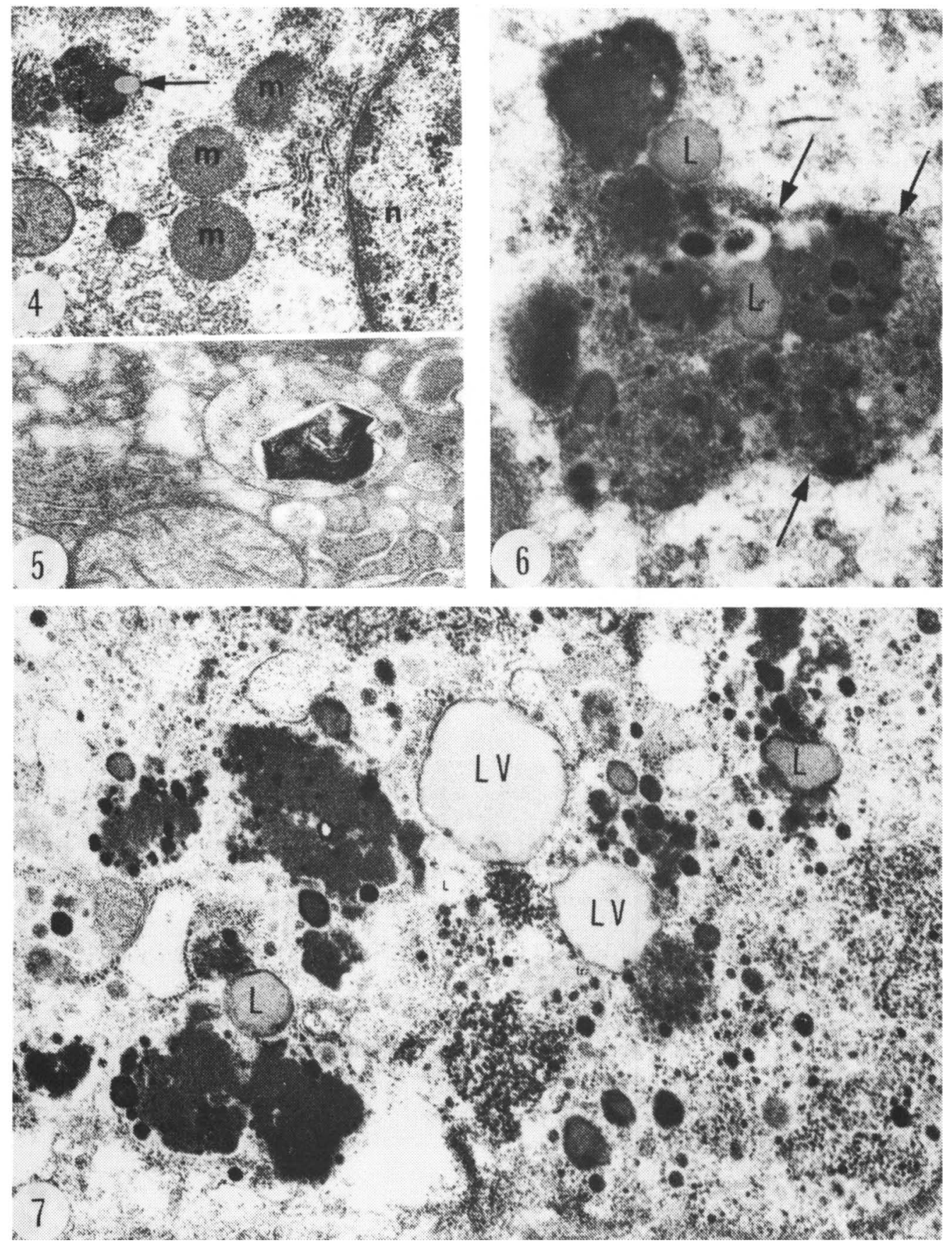

Figure 4. Electron micrograph of early changes in a hepatocyte. A lipid droplet is visible in a lipofuscin granule (arrow); $\mathrm{m}$ are mitochondria with early condensation, $\mathrm{n}$ is hepatocytic nucleus. $\times 12.000$.

Figure 5. Electron micrograph of a hepatocyte; electron dense body within a mitochondrion, possibly representing an early stage in the formation of lipofuscin. An enveloping membrane is visible. $\times 24.000$.

Figure 6. Electron micrograph of a lipofuscin deposit in the cytoplasm of a hepatocyte; enveloping membrane can be seen at arrows. $L$ are lipid droplets. $\times 30.000$.

Figure 7. Electron micrograph of heterogenous lipofuscin granules in the cytoplasm of a liver cell. $\mathrm{L}$ are lipid droplets, LV lipid vacuoles unassociated with lipofuscin. $\times 32.000$. 


\section{References}

Arias I, Bernstein L, Toffler R, Cornelius C, Novikoff $A B$, Essner $E$ : Black liver disease in Corriedale sheep: $A$ new mutant affecting hepatic excretory function. Amer. Soc. clin. Invest. 1964, 43, 1249-1250.

Bancroft JD, Stevens A: Histopathological stains and their diagnostic uses. Churchill Livingstone, Edinburgh 1975, p. 91-92.

Buer $A W$ : Om en hyppig forekommende pigmentasjon av sauelevre. (On a frequently occurring pigmentation of the liver of sheep). Skand. Vet.-Tidsskr. 1940, 30, 1-9.

de Saram WG, Gallagher CH, Goodrich BC: Melanosis of sheep liver. I. Chemistry of the pigment. Aust. vet. J. 1969, 45, 105-108.

Ghadially FN: Ultrastructural pathology of the cell and matrix. 2nd. Ed. Butterworths, London 1982, $543 \mathrm{pp}$.

Gilruth $J A$ : Melanotic infiltration of hepatic cells in sheep. Vet. J. 1910, 17, 390-393.

Krishna L, Iyer PKR, Sharma RM: Studies on the pathology of combined melanic and lipofuscin pigmentation in ovine livers: A note. Indian J. Anim. Sci. 1972, 42, 827-828.

Palmer DN, Barns G, Husbands OR, Jolly RO: Ceroid/lipofuscinosis in sheep. II. The major component of the lipopigment in liver, kidney, pancreas and brain is low molecular weight protein. J. biol. Chem. 1986, 261, 17731777.

Rowland $A C$, Whiley RS: A preliminary report on hepatic pigmentation in Falkland island sheep. Vet. Res. Comm. 1983, 6, 235-240.
Schleger AV: Histopathology of melanotic sheep liver. I. Histology and non-enzymic histochemistry. Aust. vet. J. 1970a, 46, 48-54.

Schleger $A V$ : Histopathology of melanotic sheep liver. II. Enzymic histochemistry. Aust. vet. J. 1970b, 46, 55-61.

Skepper JN, Navaratnam $V$ : Lipofuscin formation in the myocardium of juvenile golden hamsters: an ultrastructural study including staining for acid phosphatase. J. Anat. (Lond.) 1987, 150, 155-167.

Travis DF, Travis A: Ultrastructural changes in the left ventricular rat myocardial cells with age. J. Ultrastruct. Res. 1972, 39, 124-148.

Winter $H$ : Lipofuscin pigmentation of sheep liver in Australia. Nature (Lond.) 1961, 189, 674 676.

\section{Sammendrag \\ Lipofuscinavleiring $i$ leveren hos normal-slaktede sauer $i$ Norge. \\ Sauelevre med den pigmenteringsanomalien som inntil nå er kalt perilobulær levermelanose ble un- dersøkt histokjemisk og ved elektronmikroskopi. Pigmentgranula i hepatocyttene og i Kupffercel- lene ble funnet å være av lipofuscintypen, mens melanin-granula eller melanosomer ikke ble på- vist. Det blir derfor konkludert med at tilstanden bør kalles leverlipofuscinose.}

(Received January 20, 1989; accepted May 1, 1989).

Reprints may be requested from: Knut Nordstoga, Department of Pathology, Norwegian College of Veterinary Medicine, P. O. Box 8146, Dep., N-0033 Oslo 1, Norway. 